\title{
Pengaruh Kualitas Pelayanan Terhadap Kepuasan pelanggan Pada Bimbingan Belajar Anak Berkebutuhan Khusus Shechina Cikarang
}

\author{
Zahra \\ Universitas Bina Sarana Informatika \\ e-mail: zahra.zhr@bsi.ac.id
}

\begin{abstract}
Cara Sitasi: Zahra. (2019). Pengaruh Kualitas Pelayanan Terhadap Kepuasan pelanggan Pada Bimbingan Belajar Anak Berkebutuhan Khusus Shechina Cikarang. Cakrawala, 19(2), 173-178. Retrieved from doi: https://doi.org/10.31294/jc.v19i2.
\end{abstract}

\begin{abstract}
The purpose of this study was to determine the effect of service quality on customer satisfaction both jointly or in part on the guidance of the development of children with special needs Cikarang Bekasi partially and simultaneously. Data sources were obtained from questionnaires distributed to customers with a total sample of 50 people consisting of parents, students, teachers and school alumni. The data processing used is quantitative descriptive analysis. The results of the t-test processing can be concluded that there is a partial effect between tangible, reliable, responsible, assurance, empathy variables on customer development and development of children with special needs and the F test results indicate that there are simultaneous influences between tangible, reliable, responsible, assurance variables, empathy towards customer satisfaction growth and development of children with special needs Cikarang-Bekasi. From the regression equation, it can be seen that the most dominant variable influencing customer satisfaction is the reliability variable with a coefficient of 0.424 $R 2(R$ Square) test results obtained by 0.775 or $77.5 \%$, which means that customer satisfaction growth and development of children with special needs is influenced by tangible variables, reliability, responsibility, assurance, empathy of $77.5 \%$. And other factors that influence customer satisfaction with customers' growth and development of children with special needs by 5.6\%. expected the school.
\end{abstract}

Keywords: service quality, customer satisfaction, and customer loyalty.

\section{PENDAHULUAN}

Saat ini persaingan dunia usaha semakin ketat. Termasuk persaingan bisnis dalam bidang jual beli kendaraan bermotor. Kesempatan peluang pasar tidak datang begitu saja, diperlukan kreativitas bisnis yang sesuai dengan kebutuhan pasar. Untuk itu perlu adanya pengelolaan dan manajemen pasar yang mampu menjawab persaingan tersebut. Usaha tersebut perlu adanya dukungan dari segala pihak baik dari perusahaan maupun para karyawannya.(Journal \& Social, 2017).

Semakin banyaknya masyarakat yang menggunakan jasa bimbingan belajar anak berkebutuhan khusu maka kualitas pelayanan menjadi sangat penting untuk memenangkan persaingan. Dengan memahami apa yang diinginkan dan diharapkan oleh pelanggan dari kualitas pelayanan yang diberikan, maka akan didapat suatu nilai tambah tersendiri bagi bimbingan belajar yang dikelolanya tersebut. Kualitas pelayanan perlu mendapat perhatian besar dari perusahaan, karena kualitas pelayanan mempunyai hubungan langsung dengan kemampuan bersaing dan tingkat keuntungan perusahaan.kepuasan adalah perasaan senang atau kecewa seseorang yang berasal dari perbandingan antara kesannya terhadap kinerja (atau hasil) suatu produk dan harapan-harapannya. Perusahaan akan berhasil memperoleh pelanggan dalam jumlah yang banyak apabila dinilai dapat memberikan kepuasan bagi pelanggan. Ketika pelanggan telah merasa puas maka akan terjalin hubungan harmonis antara produsen dan konsumen, menciptakan dasar yang baik bagi pembelian ulang dan membentuk rekomendasi dari mulut ke mulut yang dapat menguntungkan sebuah perusahaan.(Birtha, Arifudzaki; Soemantri, Maman; Abdian, 2010).

Setiap konsumen pasti memiliki pemahaman dan pengetahuan tentang aspek pelayanan dari suatu produk. Hal inilah yang sangat berpengaruh dalam pemilihan seorang konsumen dalam memilih suatu produk atau perusahaan yang menyalurkannya. Untuk merancang strategi pemasaran efektif, pemasar harus mengerti proses pemahaman konsumen, sehingga mereka dapat merancang informasi pemasaran dengan tepat. Hal tersebut membutuhkan pertimbangan karakteristik konsumen dan lingkungan di mana konsumen terpapar informasi (Kualitas, Terhadap, \& Sukoharjo, 2015).

Kualitas pelayanan merupakan faktor dan akar penting yang mampu memberikan kepuasan bagi pelanggannya yang terkait dengan hasil prilaku 
dari mulut ke mulut seperti keluhan, rekomendasi dan pertukaran atau perpindahan. kepuasan pelanggan merupakan bagian dari pemasaran dan memainkan peran penting di pasar. Strategi pemasaran yang berorientasi pada pelanggan membuat perusahaan harus memahami perilaku maupun memenuhi kebutuhan pelanggan untuk mencapai kepuasan pelanggan. Kualitas pelayanan sebagai usaha untuk mewujudkan kenyamanan bagi pelanggan agar pelanggan merasa mendapat nilai yang lebih dari yang diharapkan. Harapan pelanggan merupakan faktor penting, kualitas layanan yang lebih dekat untuk kepuasan pelanggan akan memberikan harapan lebih dan sebaliknya(Di \& Gigi, 2016).

Kualitas pelayanan yaitu Tangibles, Reliability, Responsiveness, Assurance dan Empathy, dimensi tersebut sangat berpengaruh terhadap kepuasan pelanggan. Kelima dimensi ini yang akan digunakan untuk mengukur tingkat kualitas layanan di suatu perusahaan.Perkembangan bisnis dalam bidang jasa khususnya inspeksi, pengujian, serta sertifikasi, membuat para pebisnis tidak hanya memberikan pelayanan terbaik melainkan juga bersaing dari segi harga, pelayanan, lokasi, suasana, hingga kemudahan transaksi. (Mempengaruhi, Pedagang, Lima, \& S, 2016).

Kualitas layanan juga dapat mempengaruhi loyalitas pelanggan secara langsung dan mempengaruhi loyalitas pelanggan secara tidak langsung melalui kepuasan. Kualitas layanan mendorong pelanggan untuk komitmen ke- pada produk dan layanan suatu perusahaan sehingga berdampak kepada peningkatan market share suatu produk. Kualitas layanan sangat krusial dalam mempertahankan pelanggan dalam waktu yang lama. Perusahaan yang memiliki layanan yang superior akan dapat memaksimalkan performa keuangan perusahaan(Kualitas, 2012).

Kepuasan merupakan penilaian mengenai ciri atau keistimewaan produk, jasa, atau produk itu sendiri, yang menyediakan tingkat kesenangan konsumen berkaitan dengan pemenuhankebutuhan konsumsi. Kepuasan konsumen dapat diciptakan melalui kualitas, pelayanan dan nilai. Kunci untuk menghasikan kesetiaan pelanggan adalah memberikan nilai pelanggan yang tinggi.

Penelitian ini penting dilakukan agar dapat mengukur seberapa baik pelayanan yang telah diberikan, serta mengetahui sejauh manapelayanan yang diberikan bimbingan belajar anak berkebutuhan khusus di cikarang selama ini, yang akan berpengaruh terhadap kepuasan pelanggannya. Dengan demikian diharapkan perusahaan dapat mengetahui serta mengantisipasi secara jelas tentang apa yang dibutuhkan dan diinginkan konsumen, sehingga perusahaan dapat menerapkan strategi yang tepat untuk menangani keluhan pelanggan, meningkatkan layanannya secara lebih baik, serta dapat bersaing dalam segmentasi pasar yang ada, agar tujuan perusahaan tercapai dan dapat berkembang di masa mendatang.(Pelanggan, Loyalitas, \& Dengan, n.d.).

Kepuasan pelanggan merupakan kunci dalam menciptakan loyalitas pelanggan. Banyak manfaat yang diterima oleh perusahaan dengan tercapainya tingkat kepuasan pelanggan yang tinggi, yakni selain dapat meningkatkan loyalitas pelanggan tapi juga dapat mencegah terjadinya perputaran pelanggan, mengurangi sensitivitas pelanggan terhadap harga, mengurangi biaya kegagalan pemasaran, mengurangi biaya operasi yang diakibatkan oleh meningkatnya jumlah pelanggan, meningkatkan efektivitas iklan, dan meningkatkan reputasi bisnis perusahaan.Kepuasan pelanggan menjadi parameter penting sehingga bisnis dapat terus berkelanjutan. kepuasan pelanggan merupakan konstruk yang berdiri sendiri dandipengaruhi oleh kualitas layanan. (Pengaruh et al., n.d.).

Kepuasan atau ketidakpuasan pelanggan merupakan bagian dari pengalaman pelanggan terhadap suatu produk atau jasa yang ditawarkan berdasarkan pengalaman yang diperolehnya, pelanggan memiliki kecenderungan untuk membangun nilai- nilai tertentu. Nilai tersebut akan memberikan dampak bagi pelanggan untuk melakukan perbandingan terhadap kompetitor dari produk atau jasa yang pernah dirasakannya. Apabila sebuah perusahaan memberikan produk atau jasanya yang berkualitas baik, maka diharapkan mampu memenuhi harapan pelanggan dan akhirnya mampu memberikan nilai yang maksimal serta menciptakan kepuasan bagi pelanggandibanding kompetitorkompetitor yang ada (Aryani, 2010).

Semakin tingginya tingkat persaingan, akan menyebabkan pelanggan menghadapi lebih banyak alternatif produk, harga dan kualitas yang bervariasi, sehingga pelanggan akan selalu mencari nilai yang dianggap paling tinggi dari beberapa produk (Pelanggan et al., n.d.)

Kualitas yang rendah akan menimbulkan ketidakpuasan pada pelanggan, tidak hanya pelanggan yang makan di restoran tersebut tapi juga berdampak pada orang lain. Karena pelanggan yang kecewa akan bercerita paling sedikit kepada 15 orang lainnya. Dampaknya, calon pelanggan akan menjatuhkan pilihannya kepada pesaing. Upaya perbaikan sistem kualitas pelayanan, akan jauh lebih efektif bagi keberlangsungan bisnis. Menurut hasil riset Wharton Business School, upaya perbaikan ini akan menjadikan konsumen makin loyal kepada perusahaan (Kualitas, 2012)

Konsep dari kualitas layanan, kepuasan dan loyalitas saling berhubungan satu dengan yang lain. Secara teoritis, dalam prosesnya dapat memberikan acuan pada penelitian ini, dimana kualitas layanan mempengaruhi loyalitas baik secara langsung 
maupun mempengaruhi loyalitas secara tidak langsung melaluikepuasan pelanggan(Emosional et al., 2018).

Pusat Terapi /Klinik adalah fasilitas pelayanan pendidikan dan pelatihan kesehatan yang menyelenggarakan dan menyediakan pelayanan latihan / medis dasar dan atau spesialistik, diselenggarakan oleh lebih dari satu jenis tenaga ahli kesehatan dan dipimpin oleh seorang tenaga Ortopardagog. Jenis pelayanan / klinik dibagi menjadi beberapa bagian namun pada saat pembelajaran diberikan atau terapi kami satu padukan dalam satu paket terapi. dua yaitu pusat terapi, merupakan tumbuh kembang yang menyelenggarakan pelayanan medic dasar yang dilayani oleh dokter Psikiater, dokter anak dan dokter syaraf. Berdasarkan perijinannyapusat terapi ini ini dapat dimiliki oleh badan usaha ataupun perorangan. Untuk dapat bertahan hidup dan berkembang di dalam lingkungan yang cepat berubah dan kompetitif, Pusat Terapi Shechinah harus mengubah paradigma pengelolaan ke arah sudut pandang Pelanggan (Effect et al., 2018).

Pusat terapi Shechina merupakan tempat terapi dan belajar anak berkebutuhan khusus yang terletak di Cikarang Bekasi yang saat ini memiliki siswa berjumlah 50 siswa, dengan berbagai macam karakter dan permasalahan anak.

\section{METODOLOGI PENELITIAN}

Penulis menggunakan metode kuantitatif ( angka), karena penulis menggunakan pembobotan dari hasil kuesioner tingkat kepuasan pelanggan.

Menurut Sugiono dalam Marini dkk (2012, h.7), metode penelitian kuantitatif dapat diartikan sebagai metode penelitian yang diguinakan untuk meneliti pada populasi atau sempel tertentu.

Sampel adalah sebagian atau wakil populasi yang diteliti. Teknik pengambilan sampel yang digunakan adalah teknik accidental random sampling. Teknik accidental random sampling adalah teknik pengambilan sampel secara kebetulan dimana se- mua anggota populasi mempunyai peluang yang sama untuk dijadikan anggota sampel. Sampel yang digunakan dalam penelitian ini ditetapkan sejumlah 50 responden, dengan tujuan untuk memperoleh sampel yang lebih representatif. Sampel ini merupakan sampel homogen yaitu terdiri dari orang tua siswa, siswa, guru dan alumni tumbuh kembang anak berkebuthan khusus yang telah menggunakan jasa bimbingan belajar di cikarang. (Aryani, 2010)

Teknik pengambilan sampelnya juga menggunakan teknik random. Pengambilan sampel dilakukan $75 \%$ di hari kerja senin sampai sabtu dan $25 \%$ di hari libur yaitu minggu. Variabel merupakan suatu atribut dari sekelompok objek yang diteliti, mempunyai variasi antara satu dan lainnya dalam kelompok tersebut Variabel da- lam penelitian ini adalah: Variabel terikat yaitu variabel yang nilainya dipengaruhi oleh variabel independen. Variabel terikat dalam penelitian ini adalah kepuasan pelanggan. Variabel bebas yaitu variabel yang menjadi sebab terjadinya/terpengaruhnya variabel dependen(Ngalimin et al., 2019).

Data Primer: Sumber data pertama dalam penelitian ini adalah data primer, yaitu data yang diambil dari sumber pertama. Data primer dalam penelitian ini diambil dari jawaban kuesioner/instrumen penelitian yang diisi oleh pelanggan atau konsumen bimbingan tumbuh kembang anak di cikarang bekasi. Data sekunder: Data sekunder merupakan data primer yang diolah lebih lanjut dan disajikan baik oleh pihak pengumpul data primer atau oleh pihak lain. Data sekunder dalam penelitian ini berupa data mengenai gambaran umum bimbingan belajar, biaya belajar dan jadwal kegiatan belajar mengajar

Metode pengumpulan data

Memperoleh informasi yang relevan, akurat dan reliabel. metode dokumentasi adalah mencari data mengenai hal-hal atau variabel-variabel yang berupa catatan, transkrip, buku, jurnal, surat kabar, majalah dan sebagainya. Dalam hal ini metode dokumentasi digunakan untuk mengetahui gambaran umum perusahaan, kuesioner adalah sejumlah pertanyaan tertulis yang digunakan untuk memperoleh informasi dari responden dalam arti laporan tentang pribadinya atau hal-hal yang ia ketahui. Dalam penelitian ini kuesioner digunakan untuk memperoleh informasi dan tanggapan dari pelanggan mengenai kualitas data mengenai gambaran umum bimbingan belajar, biaya belajar dan jadwal kegiatan belajar mengajar. Kuesioner yang digunakan adalah kuesioner tertutup.Skala yang digunakan dalam penyusunan kuesioner adalah skala ordinal atau sering disebut skala likert, yaitu skala yang berisi lima tingkat preferensi jawaban. Lima tingkat preferensi jawaban yang digunakan dalam kuesioner penelitian ini yaitu: Sangat setuju, den- gan skor 5; Setuju, dengan skor 4; Cukup setuju, dengan skor 3; Tidak setuju, dengan skor 2; Sangat tidak setuju, dengan skor 1 . Analisis data yang digunakan adalah analisis deskriptif dan analisis regresi linear berganda menggunakan SPSS. Metode Analisis

\section{Uji Validitas dan Uji Reliabilitas}

Uji validitas Pengujian validitas kriteria dilakukan dengan cara membandingkan atau engkorelasikan antara nilai (skor) hasil pengukuran instrumen dengan kriteria atau standar tertentu yang dipercaya dapat digunakan untuk menilai (mengukur) suatu variabel. Pernyataan pada kuesioner dinyatakan valid jika nilai $r$ hitung (Corrected Item-Total Correlation) $>\mathrm{r}$ tabel atau tingkat signifikansi $<0,05$. Selanjuttnya, 
Realibilitas/keandalan (derajat konsistensi) adalah ukuran yang menunjukkan seberapa tinggi suatu instrument dapat dipercaya atau dapat diandalkan, artinya reliabilitas menyangkut ketepatan (dalam pengertian konsisten). Pengertian lainnya jika suatu set objek yang sama diukur berkali-kali dengan alat ukur yang sama akan diperoleh hasil yang sama.(Made, Sulistyawati, \& Seminari, 2015)

Analisis Regresi Linier Berganda

Analisis dalam penelitian ini teknik analisis data yang dipaki adala regresi linear berganda (multiple regression). Analisis regresi pada dasarnya adalah studi mengenai ketergantungan variabel dependen (terikat) dengan satu atau lebih varibel independen (variabel penjelas/bebas ) digunakan untuk menguji hipotesis yang telah dipilih.

Uji Hipotesis

Pengujian Hipotesis Secara Bersama-sama dengan Uji F, Uji F dilakukan untuk menguji signifikan koefisien korelasi atau untuk mengetahui apakah variabel bebas secara bersama berpengaruh secara signifikan atau tidak terhadap variabel terikat.

Uji masing-masing hipotesis Parsial, Uji (t)

Uji t dilakukan untuk menguji signifikan koefisien korelasi atau untuk mengetahui apakah masingmasing Variabel (X1 dan X2), berpengaruh terhadap variabel terikat $(\mathrm{Y})$.

\section{HASIL DAN PEMBAHASAN}

Metode pengujian dengan mengguna kanstatistik deskriptif dan statistic inferensial, penulis ingin menguji pengaruh antara variable bebas terhadap variable terikat. Dimana Hasil analisis deskriptif menunjukkan bahwa responden yang menja diobjek dalam penelitian initerdiri dari $58,21 \%$ orang laki-lakidan $41,79 \%$ orang perempuan.

Tabel 1. karakteristik berdasarkan usia.

\begin{tabular}{lll}
\hline Usia & Frekuensi & Persentase \\
\hline$<10$ th & 7 & $10,45 \%$ \\
\hline $10-15$ th & 12 & $43,28 \%$ \\
\hline $16-20$ th & 17 & $25,37 \%$ \\
\hline$>20$ th & 14 & $20,90 \%$ \\
\hline
\end{tabular}

Uji Asumsi Klasik

1. Uji Normalitas

Uji statistik sederhana yang sering digunakan untuk menguji asumsi normalitas adalah dengan menggunakan uji normalitas. Metode pengujian normal tidaknya distribusi data dilakukan dengan melihat nilaisignifikansi variabel, jika signifikan lebih besar dari alpha $10 \% \quad(0.1)$, maka menunjukkandistribusi data normal.

Tabel 2 Uji Validitas Tingkat Kualitas Pelayanan

\begin{tabular}{|c|c|c|c|c|}
\hline $\begin{array}{l}\text { Atribut } \\
\text { Pernyataan }\end{array}$ & / & $\begin{array}{l}\mathrm{r} \\
\text { tabel }\end{array}$ & $\begin{array}{l}\mathrm{r} \\
\text { hitung }\end{array}$ & Hasil \\
\hline Item 1 & & 0,244 & 0,456 & Valid \\
\hline Item 2 & & 0,244 & 0,541 & Valid \\
\hline Item 3 & & 0,244 & 0,466 & Valid \\
\hline Item 4 & & 0,244 & 0,368 & Valid \\
\hline Item 5 & & 0,244 & 0,566 & Valid \\
\hline
\end{tabular}

Tabel 3 Uji Validitas Tingkat Kepuasan Pelanggan

\begin{tabular}{llll}
\hline $\begin{array}{l}\text { Atribut } \\
\text { Pernyataan }\end{array}$ & r tabel & r hitung & Hasil \\
\hline item 1 & 0,244 & 0,456 & Valid \\
\hline Item 2 & 0,244 & 0,541 & Valid \\
\hline item 3 & 0,244 & 0,466 & Valid \\
\hline item 4 & 0,244 & 0,368 & Valid \\
\hline item 5 & 0,244 & 0,566 & Valid \\
\hline
\end{tabular}

Metode Analisis Data yang digunakan adalah Validitas dan Keandalan, Uji validitas digunakan untuk mengukur validitas kuesioner. Untuk itu, Pearson Product Moment sudah digunakan. Jika probabilitas korelasi kurang dari 0,05 (5\%) maka instrumen penelitian dianggap valid. Uji reliabilitas ini dalam penelitian ini menggunakan Alpha Cronbach. Dengan demikian pertanyaan tersebut menyatakan butir yang valid.

Pengolahan data dalam penelitian ini dilakukan dengan menggunakan bantuan program SPSS berdasarkan data-data yang diperoleh dari hasil penelitian yaitu dari 50 sampel yang diteliti. Untuk lebih jelasnya penelitian ini dapat dilihat pada analisis data yang akan disajikan.

\section{Tabel 3 Tabel uji korelasi}

\begin{tabular}{|c|c|c|c|c|}
\hline \multicolumn{5}{|c|}{ Correlations } \\
\hline \multicolumn{3}{|c|}{ Control Variables } & Kualitas & loyalitas \\
\hline \multirow[t]{6}{*}{ Kepuasan } & \multirow[t]{3}{*}{ Kualitas } & Correlation & 1,000 &, 042 \\
\hline & & $\begin{array}{l}\text { Significance } \\
\text { (2-tailed) }\end{array}$ & . & ,775 \\
\hline & & df & 0 & 47 \\
\hline & \multirow[t]{3}{*}{ loyalitas } & Correlation & ,042 & 1,000 \\
\hline & & $\begin{array}{l}\text { Significance } \\
\text { (2-tailed) }\end{array}$ & ,775 & . \\
\hline & & df & 47 & 0 \\
\hline
\end{tabular}


Hasil Uji Validitas untuk Kepuasan Konsumen (Y). Berdasarkan capaian koefisien Pearson Correlate loyalitas sebesar 0,042 dan kualitas sebesar 0,775. Dapat dilihat bahwa semua item mempunyai capaian koefisien Pearson Correlate lebih besar dari 0,775, itu berarti bahwa semua item yang digunakan pada Variabel Kepuasan Konsumen adalah Valid

Tabel Regresi

\begin{tabular}{lrrrr}
\hline \multicolumn{5}{c}{ Model Summary } \\
\hline & & \multicolumn{4}{c}{ Adjusted R } & \multicolumn{1}{c}{$\begin{array}{c}\text { Std. Error of } \\
\text { Model }\end{array}$} & $\mathrm{R}$ & $\mathrm{R}$ Square & Square & the Estimate \\
\hline 1 &, $150^{\mathrm{a}}$ &, 022 &, 002 & 1,99030 \\
\hline
\end{tabular}

a. Predictors: (Constant), Kepuasan

Dari hasil perhitungan diperoleh nilai t hitung untuk variabel kualitas pelayanan adalah sebesar 1,000 dan dengan menggunakan level significance (taraf signifikasi) sebesar 5\% diperoleh $\mathrm{t}$ tabel sebesar 0,775 yang berarti bahwa nilai $\mathrm{t}$ hitung lebih besar dari t tabel yaitu 1,000>0,775. Nilai signifikasi t kurang dari $5 \%$ $(0,000)$, menandakan bahwa kualitaspelayanan (X1) mempunyai pengaruh yang positif dan signifikan terhadap kepuasan pelayanan (Y). Dengan demikian dapat disimpulkan bahwa Ho ditolak dan H1 diterima,sehingga hipotesis yang menyatakan kualitas pelayanan mempunyai pengaruh yang positif terhadap kepuasan pelanggan dapat diterima.

Dari hasil perhitungan diperoleh nilai $t$ hitung untuk variabel harga adalah sebesar 4,879 dan dengan menggunakan level significance (taraf signifikasi) sebesar5\% diperoleh t tabel sebesar 0,775 yang berarti bahwa nilai $\mathrm{t}$ hitung lebih besar dari $\mathrm{t}$ tabel yaitu menandakan bahwa harga (X2) mempunyai pengaruh yang positif dan signifikan terhadap kepuasan pelanggan (Y). Dengan demikian dapat disimpulkan bahwa Ho ditolak dan $\mathrm{H} 2$ diterima, sehingga hipotesis yang menyatakan harga mempunyai pengaruh yang positif terhadap kepuasan pelanggan dapat diterima.

Dari hasil perhitungan diperoleh nilai t hitung untuk variabel lokasi adalah sebesar0,775 dan dengan menggunakan level significance (taraf signifikasi) sebesar $5 \%$ diperoleh $t$ tabel sebesar 1,000 yang berarti bahwa nilai t hitung lebih besar dari t tabel yaitu 0,424 >0,775. Nilai signifikasi t kurang dari $5 \%(0,001)$, menandakan bahwa lokasi (X3) mempunyai pengaruh yang positif dan signifikan terhadap kepuasan pelanggan (Y). Dengan demikian dapat disimpulkan bahwa Ho ditolak dan H3 diterima, sehingga hipotesis yang menyatakan lokasi mempunyai pengaruh yang positif terhadap kepuasan pelanggan dapat diterima.

\section{KESIMPULAN}

Hasil penelitian menunjukkan bahwa kualitas layanan terbukti berpengaruh secara signifikan terhadap kepuasan pelangga. Dimensi terkuat dalam menjelaskan kualitas layanan berturut- turut adalah reliability, responsiveness, assurance, empathy, dan tangibility. Selain itu, hasil penelitian menunjukkan terdapat pengaruh yang kuat dan positif antara variabel kualitas layanan bimbingan belajar Shechina Cikarang terhadap kepuasan pelanggan. Hal ini terbukti dari hasil penelitian yang menunjukkan bahwa sebesar $72,9 \%$ variabel kepuasan pelanggan dapat dijelaskan oleh variabel kualitas layanan, sedangkan sisanya sebesar $27,1 \%$ dipengaruhi oleh faktor lain di luar variabel kualitas layanan. Hasil penelitian lain menunjukkan bahwa terdapat pengaruh yang kuat dan positif antara kualitas layanan terhadap loyalitas pelanggan bimbingan belajar Shechina Cikarang. Hal ini ditunjukkan oleh sebesar 91\% variabel loyalitas pelanggan yang dapat dijelaskan oleh variabel kualitas layanan, sedangkan sisanya sebesar 9\% dipengaruhi oleh variabel lain di luar kualitas layanan.

\section{REFERENSI}

Aryani, D. W. I. (2010). Pengaruh Kualitas Layanan terhadap Kepuasan Pelanggan dalam Membentuk Loyalitas Pelanggan, 17, 114126.

Birtha, Arifudzaki; Soemantri, Maman; Abdian, F. (2010). Aplikasi Sistem Informasi Persediaan Barang pada Perusahaan Export Hasil Laut Berbasis Web. Transmisi, 12(1), 1.

Di, P., \& Gigi, P. (2016). PUSKESMAS SUKAWATI II TAHUN 2015, 4(2), 78-90.

Effect, T., Health, O., Quality, S., Out, O., Satisfaction, P., Cardiac, I., ... Sakit, R. (2018). 1*, 2 , 3 1, l(2), 64-75.

Emosional, K., Msdm, M., Ekonomi, F., Pandanaran, U., Banjarasari, J., \& No, B. (2018). 12 1.1, 1-12.

Journal, D., \& Social, O. F. (2017). DIPONEGORO JOURNAL OF SOCIAL AND POLITICAL Tahun 2017, Hal 1-8 http://ejournals1.undip.ac.id/index.php/.

Kualitas, P. (2012). Management Analysis Journal, 1(4).

Kualitas, P., Terhadap, P., \& Sukoharjo, M. (2015). Pengaruh kualitas pelayanan terhadap kepuasan konsumen pada dealer pt. ramayana motor sukoharjo, 13(1), 1-12.

Made, N., Sulistyawati, A., \& Seminari, N. K. (2015). KEPUASAN PELANGGAN RESTORAN INDUS, 4(8), 2318-2332.

Mempengaruhi, F. Y., Pedagang, P., Lima, K., \& S, C. M. (2016). Majalah Ekonomi _ ISSN No. 1411-9501_Vol. XXI No. 2 Des 2016 Christina Menuk S - Tony Susilo Wibowo, 
(1411), 286-294.

Ngalimin, I. G. Q., Mandagie, Y., Ekonomi, F., Bisnis, D., Manajemen, J., \& Manado, U. (2019). Strategi Relationship Marketing Dan Promosi Pengaruhnya Terhadap Kepuasan Konsumen Di Matahari Departement Store Mega Mall Strategy Of Relationship Marketing And Promotion Of The Effect On Customer Satisfaction In The Departement Store Mega Mall Manado Oleh:, 7(1), 571580 .

Pelanggan, K., Loyalitas, T., \& Dengan, P. (n.d.). Pengaruh Kualitas Pelayanan, Tarif Layanan Jasa Dan Kepuasan Pelanggan Terhadap Loyalitas Pelanggan Dengan Nilai Pelanggan Sebagai Variabel Intervening (Studi Pada Perusahaan Bengkel Mobil PT Hartono Raya Motor Semarang).

Pengaruh, A., Pelayanan, K., Dan, H., Nurhalimah, S., Hasiholan, L. B., \& Harini, D. C. (n.d.). ( Studi pada Bengkel Garasi di Ungaran ), 1-15.

\section{PROFIL PENULIS}

Zahra S.Pd. MM, Lahir di Jakarta, 22 Mei 1971, Menamatkan kuliah Pendidikan S1 di Universitas Negeri Jakarta dan Pendidikan S2 di Mercubuana Jakarta dengan jurusan Magister Managemen, dari tahun 2009 Saya mengajar di Universitas Bina Sarana Informatika, Bidang Ajar yang saya tempuh adalah, Character Building, Dasar-dasar Manajemen dan Enterpreneurship. Saya tinggal di Kota Bekasi, Prestasi yang saya miliki adalah selain saya mengajar di kampus, saya seorang konsultan (Ortopaedagog) anak-anak berkebutuhan khusus dan saya dapat mengajar anak-anak berkebutuhan khusus seperti anak autisme, down syndrom, anak kesulitan dalam belajar ( Disleksia, Diskalkulia, Disgrafiah). 